\begin{tabular}{l}
\hline OPEN OA ACCESS Freely available online \\
http://www.banglajol.info/index.php/BJID/index \\
Review Article \\
Bangladesh Journal of Infectious Diseases \\
December 2020, Volume 7, Number 2, Page 95-98 \\
ISSN (Online) 2411-670X ISSN (Print) 2411-4820 \\
DOI: https://doi.org/10.3329/bjid.v7i2.51520
\end{tabular}

\title{
Ivermectin the Promising Drug to Stave off the COVID-19 Crisis: A Review
}

\author{
Zakia Jahan ${ }^{1}$, Masudul Hassan ${ }^{2}$
}

${ }^{1} \mathrm{MPH}$ from the George Washington University, USA. Director of Center for Human Development; ${ }^{2} \mathrm{MD}$ in Cardiologist, Professor, \& Director, Metropolitan Learning Institute, New York, USA

[Received: 12 July 2020; Accepted: 30 August 2020; Published: 1 December 2020]

\begin{abstract}
The Coronavirus disease 2019 (COVID-19) outbreak, forcing us to face unprecedented moments in the world. The huge devastating impact of the world due to the covid-19 attack causes the brink of no return. However, there is no proven and specific treatment for Covid -19. Very few medications have received Emergency Use of Authorization. A recent in vitro study was the first time to find out and to assess the antiviral effect of Ivermectin on COVID-19. The study showed that Ivermectin was active against COVID19-infected cells, was able to kill effectively almost all viral particles within $48 \mathrm{~h}$. In these moments of crisis, FDA-approved ivermectin is a ray of hope. [Bangladesh Journal of Infectious Diseases, December 2020;7(2):95-98]

Keywords: Covid-19; pandemic; Ivermectin.

Correspondence: Dr. Zakia Jahan, 72nd Street, Apt \# 35, Jackson Heights, NY 11372, USA; Email: zakiamonzur@gmail.com; Cell No: 001-646-851-3824

Conflict of interest: Authors declare that there is no conflict of interest.

Funding agency: The author didn't receive any kind of funding for this study.

Contribution to authors: Jahan Z, Hassan M involved in protocol preparation, data collection, and literature search up to manuscript writing involved in literature search, preparation, and revision of this manuscript.

How to cite this article: Jahan Z, Hassan M. Ivermectin the Promising Drug to Stave off the COVID-19 Crisis: A Review. Bangladesh J Infect Dis 2020;7(2):95-98

Copyright: @2020. Jahan and Hassan. Published by Bangladesh Journal of Infectious Diseases. This article is published under the Creative Commons CC BY-NC License (https://creativecommons.org/licenses/by-nc/4.0/). This license permits use, distribution and reproduction in any medium, provided the original work is properly cited, and is not used for commercial purposes.
\end{abstract}

\section{Introduction}

The Coronavirus disease 2019 (COVID-19) outbreak, forcing us to face unprecedented moments in the world. The huge devastating impact of the world due to the covid-19 attack causes the brink of no return. The exponentially soaring infection rate and massive death toll across the globe are alarming. A highly contagious and virulent virus causes a huge global Burden. Lack of effective specific treatments is a significant problem now. It is utterly uncertain when proper successful, and effective treatments would be available. In these moments of crisis, Ivermectin is a ray of hope.

Although there is no proven and specific treatment for Covid-19, very few medications have received Emergency Use of Authorization. In vitro study findings is Ivermectin was active against COVID19-infected cell ${ }^{1}$. Ivermectin is an FDA-approved broad-spectrum anti-parasitic agent. Also, Ivermectin is extensively obtainable. Ivermectin has shown to have antiviral activity against a broad range of viruses. So, it is potential for repurposing ${ }^{1}$. 
Ivermectin has secured its place on the World Health Organization's List of Essential Medicines ${ }^{2}$.

\section{COVID-19: A Global health burden}

The World Health Organization declare COVID-19 as a global health emergency. It is a single-stranded RNA virus also name as SARS-CoV-2 that causes severe respiratory distress syndrome ${ }^{3}$. A novel coronavirus 2019 first spark as an outbreak in China in December 2019, caused severe epidemics around the world and followed by a pandemic. Though some corona patients reached a devastating epidemics outcome, others show mild to moderate respiratory infections, like the common cold ${ }^{4}$.

\section{Proven Safety of Ivermectin}

Ivermectin shows the capacity of beneficiary effects to treat various diseases, with its antimicrobial, antiviral, and anti-cancer properties as a surprising drug. Ivermectin is an old-fashioned drug that has been used for several years to treat many infectious diseases. When orally prescribed, it has shown a less adverse effect and the right safety criteria. Ivermectin was point out in the late 1970s and first got acceptance for animal use in 1981. Ivermectin plays a significant role in several biological mechanisms; therefore, it could act as a strong and potential candidate in the treatment of a wide variety of viruses, along with COVID-19 as well as other types of positive-strain single-stranded RNA viruses. However, more studies and clinical trial research are necessary for the conclusive evidence of the potential efficacy of Ivermectin ${ }^{5}$. A recent in vitro study was the first time to find out and to assess the antiviral effect of Ivermectin on COVID-19. The study showed that Ivermectin was active against COVID-19-infected cells, was able to kill effectively almost all viral particles within 48 hours $^{1}$.

\section{Discussion}

Beneath the aegis of the Academy of Advanced Medical Education team of senior doctors met on 19th July'20 to evaluate the effect of Ivermectin used in COVID 19 (Novel Coronavirus Disease 2019) management. End of the discussion, they came to the point that, since Coronavirus, showing its antiviral properties, it is cost-effective, easily accessible with less adverse effect, and with good tolerance so that Ivermectin can be a potential medicine for preventive prophylaxis and treatment of Coronavirus infected people ${ }^{6}$.

Ivermectin shows strong antiviral properties according to recent research ${ }^{7}$. It can convert RT-PCR negative promptly ${ }^{1}$. Ivermectin is easily accessible, cost-effective, and safe without any significant adverse effects $^{8}$. In the severity of COVID-19, especially in the earlier viremic phase, it can be used $^{8}$. Also, it can be used in combination with other drugs, like Hydroxychloroquine, azithromycin, doxycycline ${ }^{9}$.

In April 2020, Monash University's Biomedicine Discovery Institute (BDI), with the Peter Doherty Institute of Infection and Immunity (Doherty Institute) at Royal Melbourne Hospital has Published their research article Caly et al. and mentioned that In vitro, the concentration of Coronavirus could decrease by applying that a single dose of Ivermectin (an antiparasitic drug). A single dose can control viral replication within 24 to $48 \mathrm{~h}$ in our system and effect $\sim 5000$-fold reduction in virus at 48 hours in cell culture. and maintenance of development at 72 hours ${ }^{1}$.

In vitro study, the Vero/hSLAM cells contaminated and infected with the SARS-CoV-2 or COVID-19 virus were exposed to $5 \mu \mathrm{M}$ ivermectin in $48 \mathrm{~h}$, and they found that there is a reduction of 5000-fold in viral RNA compared with the control group. Also, authors came to learn and noted a 93-99.8\% reduction in viral RNA for Ivermectin versus DMSO control $^{1}$. The authors found and acknowledged that the drug might have to produce antiviral effects by inhibiting the importin (IMP) $\alpha / \beta$ receptor, which is essential and responsible for transmitting viral proteins into the host cell nucleus. The authors suggest human studies to confirm the potential advantage of Ivermectin in the treatment of COVID19. However, this study was the first time to assess and ensure Ivermectin's antiviral effect on COVID$19^{1}$.

Ivermectin is well-tolerated, and side effects have been mild and transient ${ }^{7}$. In the liver, with the help of CYP450-3A47, it is metabolized primarily. It has 16 hours plasma half-life and is almost entirely excreted in feces with few kidneys' clearances. Therefore, in renal failure patient doesn't require dose adjustment ${ }^{10}$.

\section{Ivermectin in Specific Condition}

Ivermectin is not recommended due to no adequate studies shows the safety of Ivermectin in pregnant women. Studies in animals have shown teratogenic effect an increase in congenital disabilities. Ivermectin also passes in breast milk, so the use of Ivermectin is not recommended for nursing mothers. Pediatric use is not recommended due to safety and effectiveness in children below five years, and under $15 \mathrm{~kg}$ is not established ${ }^{11}$.

In Progress, Clinical Trials, and Positivity in Various Countries 
USA STUDY I: At four Florida hospitals, a retrospective cohort study showed significantly lower mortality who received Ivermectin compared with standard care ${ }^{12}$. At Broward Health Medical Center in Fort Lauderdale, Florida, a pulmonary care physician Jean-Jacques Rajter, MD, after observing the tremendous promising findings of the in vitro study back in April, started using Ivermectin to treat COVID-19 in critical patients ${ }^{13}$.

Bangladesh study, for covid -19 symptoms relief Ivermectin-Doxycycline combination therapy has an excellent successful outcome with reduced recovery duration, side effects ${ }^{9}$. Indian council of medical research is now exploring the benefits of Ivermectin and doxycycline as a proper possible therapy for COVID-19 ${ }^{14}$. Ivermectin got approval for management of mild symptoms of COVID-19 In Peru and Bolivia. In the north-eastern Beni region, Ivermectin also using ${ }^{15}$.

\section{Real-World Experience}

The trial Site was found from an interview of different doctors of the other country. After publishing research from Australia's Monash University, there is vast approval for an Ivermectinbased protocol from doctors from Bangladesh and India to the Dominican Republic, Peru, Columbia, and Iraq to the United States. This approval shows very successful health outcomes. A French company called Medincell also announced an ivermectinbased COVID-19 therapy. Professor Thomas Borody is the most famous, world-renowned leader investigator and the developer of the world's first cure triple therapy for peptic ulcers, which saved millions of lives worldwide; he touts that FDA and TGA approved Ivermectin. Also mentioned, Ivermectin should use instantly to fight against the pandemic. The leader Borody employed the Ivermectin triple therapy. Dr. Borody calls it an "Australian Triple Therapy," which mentioned a triple therapy of Ivermectin, zinc, and an antibiotic (Doxycycline-TGA and FDA approved tetracycline antibiotic) quickest and safest shielded to fight against the outbreak within 6-8 weeks. He also stated Ivermectin and doxycycline is TGA and FDA agreed, and it has good safety character. The same treatment method is used from Bangladesh and India to South America. Also, Ivermectin is known as a wonder drug from japan since it has established a safety profile ${ }^{16}$.

In recent press, the professor stated that antiviral scientific research and identified the combination of three drugs could be prescribed by doctors promptly. Borody also mentioned that at home, as a preventive medicine to reduce the need for hospitalization at the maximum curative dose, the tablets can be taken by a high-risk group or tested positive. It will reduce the extremity and length of the infection. To get successful and specific treatment options for COVID-19, hundreds to thousands of doctors, more than 30 formal clinical trials, many more dozens of real-world observational initiatives, and randomized controlled trials already using the medicine ${ }^{16}$.

\section{Conclusion}

The COVID-19 is an international concern and causing a severe global health threat. It is a public health emergency, and the CDC is committed to staving off its spread. Further control study on a large scale is essential to get conclusive evidence about Ivermectin's effectiveness and success. Nevertheless, the results of the study findings and reviewing additional research is showing very positive effects. We request International organizations, Stakeholders, and other medical team members to initiates these unique observational findings and promptly give it a trial and clearance because these FDA-approved drugs show excellent safety and efficacy reviews for many years. Ivermectin is very cost-effective, can save a lot of life, even in inadequate setting resources.

\section{References}

1. Caly L, Druce JD, Catton MG, Jans DA, Wagstaff KM. The FDA-approved Drug Ivermectin inhibits the replication of SARS-CoV-2 in vitro. Antivir Res 2020:104787

2. World Health Organization. World Health Organization model list of essential medicines: 21st list 2019. Geneva: World Health Organization, 2019; hdl:10665/ 325771. WHO/MVP/EMP/IAU/2019.06. License: CC BYNC-SA 3.0 IGO

3. Sohrabi C, Alsafi Z, O'Neill N, et al. World Health Organization declares global emergency: a review of the 2019 novel coronavirus (COVID-19). Int J Surg. 2020; 76:71

4. Shrikrushna et al. 2020. A review on corona virus (covid19). WJPLS 2020;6(4):109-115

5. Heidary F, Gharebaghi R. Ivermectin: a systematic review from antiviral effects to COVID-19 complementary regimen. J Antibiot (Tokyo). 2020;73(9):593-602

6. Vora A, Arora VK, Behera D, Tripathy SK. White paper on Ivermectin as a potential therapy for COVID-19. The Indian journal of tuberculosis, 2020;67(3), 448-451

7. Sharun K, Dhama K, Patel SK. Ivermectin, a new candidate therapeutic against SARS-CoV-2/COVID-19. Ann Clin Microbiol Antimicrob. 2020;19(1):23

8. Banerjee K, Nandy M, Dalai CK, Ahmed SN. The battle against COVID 19 pandemic: what we need to know before we "test fire" Ivermectin. Drug Res (Stuttg) 2020

9. Chowdhury AT, Shahbaz M, Karim MR, Islam J, Dan G, He S. A comparative observational study on IvermectinDoxycycline and Hydroxychloroquine-Azithromycin therapy on COVID19 patients [cited 2020 July 19] [Preprint] 2020. https://www.researchgate.net/publication/342159343

10. Alam MT, Murshed R, Bhiuyan E, Saber S, Alam R, Robin R. A Case Series of 100 COVID-19 Positive Patients Treated with Combination of Ivermectin and Doxycycline. Journal of Bangladesh College of Physicians and Surgeons 2020;38:10-15 
11. McCarthy J., Laukas A., Hotez P.J. Chemotherapy of Helminth infections (Chapter 51). Goodman Gilman's The Pharmacological Basis of Therapeutics, 12 ed. New York: McGraw-Hill Companies, Inc; 2011. pg- 1456 Goodman and Gilman's The Pharmacological Basis of Therapeutics 12th edition, pg-1456

12. Cennimo David J. What is the role of antiparasitic drug ivermectin in the treatment of corona virus disease 2019 (Covid19)? Available

from: https://www.medscape.com/answers/2500114-197513/what-isthe-role-of-the-antiparasitic-drug-ivermectin-in-the-treatmentof-coronavirus-disease-2019-covid-19 Updated: Jul 02, 2020. [Internet] [cited 2020 July 19]

13. Hlavinka E. Ivermectin for COVID-19: Worth a Shot? [Internet]. MedpageToday. 2020 [cited 2020 Sep 9]. Available from: reports/exclusives/88310
14. India - Trial Site News [Internet] ICMR - India's national research agency-investigating ivermectin \& doxycycline as potential treatment for COVID-19. 2020 Jun. Available from: https://www.trialsitenews.com/icmr-indias-national-researchagency-investigating-ivermectin-doxycycline-as-potentialtreatment-for-covid-19/ [Internet]. [cited 19 July 2020]. 15. India - Trial Site News [Internet] Ivermectin usage accelerates while the need for data is real: how about an ivermectin registry? 2020 May. Available from: https://www.trialsitenews.com/ivermectin-usage-accelerateswhile-the-need-for-data-is-real-how-about-an-ivermectinregistry/ [Internet]. [cited 19 July 2020].

16. Well-respected Australian researcher: Consider triple therapy (Ivermectin, zinc, doxycycline) for COVID-19 [Internet]. Trialsitenews.com. 2020 [cited 2020 Sep 10]. Available from: https://www.trialsitenews.com/well-respectedaustralianresearcher-consider-triple-therapy-ivermectin-zincdoxycycline-for-covid-19/ 